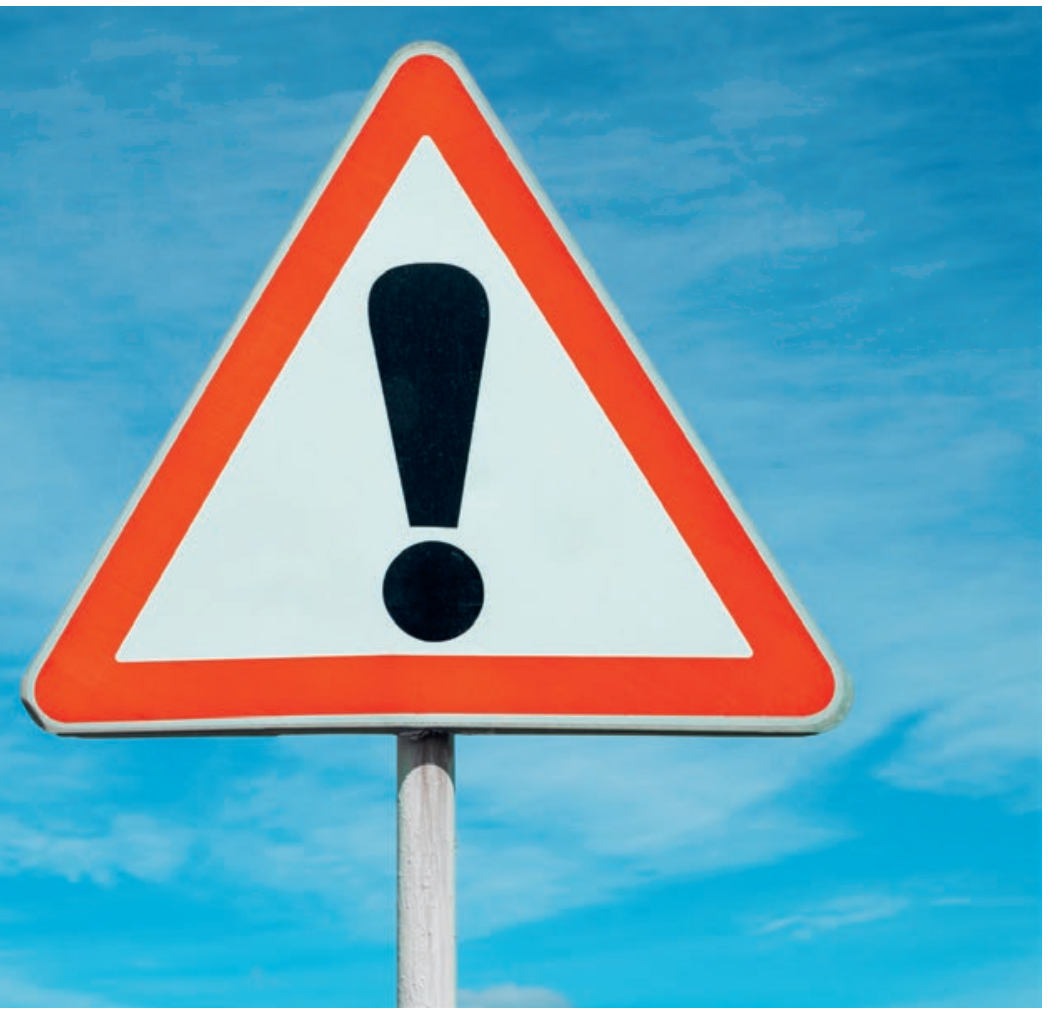

\title{
Wissenschaftsjournals fordern Engagement der Ärzteschaft in der Umweltpolitik
}

\section{Rahel Gutmann}

Junior Redaktorin der Schweizerischen Ärztezeitung

Der weltweite Temperaturanstieg und die Zerstörung der Umwelt schreiten mit beängstigender Geschwindigkeit voran. Die Auswirkungen davon haben weitreichende Folgen für unsere Gesundheit. Über 200 Fachzeitschriften aus dem Gesundheitsbereich rufen deshalb zum sofortigen Handeln auf.

Das Jahr 2021 soll zu dem Jahr werden, in dem die Lösung der Klima- und Umweltkrise endgültig und radikal angegangen wird und «die Welt endlich ihren Kurs ändert». Das fordern die Redaktionen von Gesundheitsfachzeitschriften aus der ganzen Welt in einem gemeinsamen Editorial und wenden sich damit an die UNO und die einzelnen Regierungen [1]. Als grösste Herausforderungen sehen die Autorinnen und Autoren die drohende Klimaerwärmung um über 1,5 Grad und die fortschreitende Zerstörung der Umwelt. Diese wür- den schon jetzt die Gesundheit vieler Menschen beeinträchtigen und zwar vor allem in Ländern des globalen Südens.

\section{Wohlhabende Nationen müssen handeln}

In der Pflicht stünden nun die wohlhabenden Nationen, fordern die Verfasserinnen und Verfasser des Editorials, das unter anderem in den britischen Wissenschaftspublikationen The Lancet, The BMJ und dem New 
England Journal of Medicine (NEJM) erschienen ist. Diese Nationen hätten durch ihr Verhalten massgeblich zur Krise beigetragen, während die Auswirkungen in erster Linie ärmere Länder treffen würden und somit diejenigen, die am wenigsten dafür könnten.

\section{Solidarität ist gefragt}

Das sei ein Nährboden für zukünftige Konflikte, weshalb die Massnahmen zur Eindämmung der Krise proportional gerecht zwischen den Ländern aufgeteilt werden müssten. Denn ähnlich wie bei der Covid-19-Pandemie sei eine global gedachte Solidarität unabdingbar. Und ebenso wie bei der Pandemie müssten sofort weitreichende Ressourcen zur Verfügung gestellt werden.

\section{Health Professionals an vorderster Front}

Auch die Gesundheitsfachpersonen seien gefordert, um die Klimakrise in den Griff zu kriegen. Es sei ihre Aufgabe, über die Gefahren für die Gesundheit aufzuklären und politischen Druck aufzubauen. Darüber hinaus sollten sie sich gemeinsam für ein nachhaltiges

\section{Die Massnahmen zur Eindämmung der Krise} müssten proportional gerecht zwischen den Ländern aufgeteilt werden.

Gesundheitswesen bis zum Jahr 2040 einsetzen. Eric Rubin, Chefredaktor des NEJM, ist überzeugt, dass es nicht nur Aufgabe von Gesundheitsfachpersonen sei, neue Gesundheitsbedürfnisse $\mathrm{zu}$ antizipieren, sondern sich auch aktiv für die Eindämmung der Klima- krise einzusetzen [2]. Diese Ansicht teilen die Mitglieder der UK Health Alliance, einer Vereinigung von Gesundheitsfachpersonen, die sich für Massnahmen gegen den Klimawandel einsetzt, und ebenfalls am Editorial beteiligt ist.

Mit ihrem Editorial schliessen sich die Zeitschriften den Appellen von Gesundheitsfachpersonen und Forschenden an, die seit Jahren vor den schädlichen Auswirkungen der fortschreitenden Klimaerwärmung

Die grössten Herausforderungen seien die drohende Klimaerwärmung um über 1,5 Grad und die fortschreitende Umweltzerstörung.

und Umweltzerstörung warnen. Als Erscheinungsdatum haben sie den 6 . September gewählt und wollen damit bewusst vor der Weltnaturschutzkonferenz in Kunming im Oktober und der Klimakonferenz in Glasgow Anfang November auf die Dringlichkeit des Themas aufmerksam machen.

Neben der Beschreibung der düsteren Aussichten enthält das Editorial auch einen Hoffnungsschimmer: Sollte der erhoffte Kurswechsel zustande kommen, so wäre das durch die erwartete Verbesserung der Luftund Nahrungsqualität sowie der Wohnbedingungen vielerorts nicht nur unserer Gesundheit zuträglich, sondern würde die Lebensqualität insgesamt steigern.

Bildnachweis

Aleksandr Gerasimov | Dreamstime.com

Literatur

1 www.bmj.com/content/374/bmj.n1734

2 www.bmj.com/content/374/bmj.n2177 